Article

\title{
What's (Not) on the Map: Landscape Features from Participatory Sketch Mapping Differ from Local Categories Used in Language
}

\author{
Flurina M. Wartmann ${ }^{1, *,+}$ (ID) and Ross S. Purves ${ }^{1,2}$ \\ 1 Geography Department, University of Zurich, Winterthurerstr. 190, CH-8057 Zurich, Switzerland \\ 2 University Research Priority Programme Language and Space, University of Zurich, Freiestrasse 16, \\ CH-8032 Zurich, Switzerland; ross.purves@geo.uzh.ch \\ * Correspondence: flurina.wartmann@ed.ac.uk; Tel.: +44-131-650-8163 \\ + Current address: Institute of Geography, School of Geosciences, University of Edinburgh, UK.
}

Received: 25 September 2017; Accepted: 1 November 2017; Published: 5 November 2017

\begin{abstract}
Participatory mapping of local land use as the basis for planning and decision-making has become widespread around the globe. However, still relatively little is known about the conceptual underpinnings of geographic information produced through participatory mapping in given cultural and linguistic settings. In this paper, we therefore address the seemingly simple question of what is (not) represented on maps through an exploratory case study comparing land use categories participants represented on sketch maps with categories elicited through more language-focused ethnographic fieldwork. To explore landscape categorization, we conducted sketch mapping with 29 participants and in-depth ethnographic fieldwork with 19 participants from the Takana indigenous people in the Bolivian Amazon. Sketch mapping resulted in 74 different feature types, while we elicited 156 landscape categories used in language, of which only 23 overlapped with feature types from the sketch mapping. Vegetation categories were highly diversified in language but seldom represented on maps, while more obviously anthropogenic features were represented on sketch maps. Furthermore, participants seldom drew culturally important landscape categories such as fallow plots or important plant harvesting sites on maps, with important potential consequences for natural resource management.
\end{abstract}

Keywords: land use mapping; participatory mapping; cognitive mapping; community mapping; sketch maps; landscape characterization; landscape ethnoecology

\section{Introduction}

Land use change has come to the center of attention as a massive global environmental issue [1,2], and, with it, the need for land cover and land use data as the basis for understanding the complex interactions between people and the environment [3]. However, such data are no longer seen as an absolute 'truth', but as an abstraction of reality that is embedded in political, social and institutional contexts [4-7]. Depending on the context in which information on land cover and land use is created can have very tangible consequences. Examples range from conflicts between indigenous people and forestry officials over the mapping and use of 'forest' [8], to the marginalization of local people and their land management practices by (mis)representing land cover as land use data [9]. It has been argued that one of the ways in which such conflicts could be mitigated is to give people a more active role in the creation and use of geographic information, for example through applications of participatory mapping and Participatory GIS, or PGIS $[10,11]$. One of the most common applications for PGIS is the mapping of resource distribution and land use [12-16]. Research on PGIS has addressed questions ranging from the technologies of how mapping is done, over who participates, to the applications 
and power of the resulting maps [17-24]. However, while a considerable body of literature has dealt with who is participating in the mapping process and to what effect, little research has explored the definitions and implications of what is being mapped. The latter is essentially an ontological question about how reality is abstracted into a set of categories that are represented on maps and in GIS [25]. Furthermore, it is unclear how well features documented through participatory mapping of land use mirror how people refer to and interact with their environment, particularly as documented through alternative, often more ethnographically influenced, approaches. Empirical studies in fields such as landscape ethnoecology and linguistics document the diversity of ways in which people parcel up the world into culturally shared landscape categories expressed in language [26-28]. As the distinction between land use and land cover is a Western scientific concept that is not typically reflected in language, we here use the more holistic definition of landscape brought forward by Johnson and Hunn ([28], p.1): 'We emphasize landscape as perceived and imagined by the people who live in it, the land seen, used and occupied by the members of a local community', which encapsulates both land cover and land use. Despite emerging evidence for the diversity of landscape categorizations in different languages and cultures, and, as we have stated above, evidence that the choice of what categories to represent on maps has practical implications, there is a lack of research on features represented through PGIS approaches in different cultural and linguistic contexts. We thus pose the following research questions:

1. What landscape categories do individuals choose to represent on sketch maps and how do they go about doing so?

2. To what extent do the categories captured by sketch mapping differ from landscape categories used in language?

To investigate these questions, we conducted an exploratory case study in the Bolivian Amazon rainforest, where land use is increasingly mapped and managed through the use of GIS, and contestations about resource use, to some extent, revolve around their representations on maps and in GIS [29]. In our study, we investigated features that participants drew during sketch mapping and compared these features with the landscape categories elicited through language-based ethnographic fieldwork. Our goal is to explore similarities and differences between features represented on sketch maps and landscape categories used in everyday language. We paid particular attention to was not represented on sketch maps, yet important in the landscape ethnoecology of local groups as elicited by us. For our case study, we combined sketch mapping with field walks and interviews about local landscape categories. We show that these approaches differ not only in the number of elicited categories, but also in the type of geographic information that is collected. We then discuss our results and highlight implications for the collection of geographic information on land use. The contribution of this study is twofold. In analyzing the feature types represented on sketch maps, as well as the choice of perspective and abstraction, our study offers insights into the conceptual underpinnings of geographic information elicited through this method. Furthermore, by comparing sketch mapping with a language-based approach, we highlight blind spots of the sketch mapping method that can be mediated through ethnographic methods focused on local categorizations of landscape.

\section{Background}

We review work in two areas: sketch mapping and the elicitation of landscape categories. We refer to sketch maps as hand-drawn representations using pen and paper or other materials [30]. Importantly, sketch maps are produced without underlying topographic maps or aerial images as guidance, setting them apart from other participatory mapping methods [13,22]. In development cooperation practice, sketch maps are a key component of Rapid Rural Appraisal [11] and form part of many PGIS initiatives [20,31]. From a research perspective, sketch maps have their roots in behavioral geography and psychology, where they are often used to study people's spatial concepts and mental images of their surroundings, mostly in urban environments [32-36]. Sketch maps have 
been found to be based on heuristics, often non-Euclidean and, importantly, need not take a map-like form $[37,38]$. Indeed, although the term sketch map contains the word 'map', it has been criticized as an unfitting metaphor for representations that contain separate pieces of information such as memory snippets of maps or routes taken [36]. Apart from behavioral geographers and psychologists, anthropologists have applied sketch mapping to study indigenous spatial concepts [39,40], identity and performance during mapping processes [41], as well as emotions and memories people relate to certain places [42]. Gieseking [42] proposed a theoretically grounded approach for analyzing sketch maps, with 57 components, including the number and scale of features drawn, and the use of different perspectives. Furthermore, she empirically tested the approach with sketch maps drawn by 32 former college students about their experience on campus, finding that size emphasized areas of relevance and that items drawn at the center highlighted importance. Wang and Worboys [30] proposed a conceptual framework for sketch map interpretation based on five representational levels, assuming an aerial perspective in sketch maps and that features can be automatically extracted from basic geometric shapes. Apart from such investigations, there appears to have been little research on the conceptual and theoretical underpinnings of sketch maps, and, crucially, on what is being mapped. This lack of research on the features resulting from participatory mapping is in stark contrast to a growing body of literature on landscape categorization. We distinguish two main strands of research. Firstly, in linguistics, empirical studies have shown the diversity of ways in which people parcel up the world into culturally shared categories expressed in language $[27,28,43]$. These categories are often language-specific and difficult to translate [26,44]. Secondly, landscape ethnoecology focuses on ethnographic field work, often in conjunction with ethnobotanical analysis, for investigating landscape categories and their biological and cultural underpinnings [28]. To better understand what features are (not) represented on sketch maps, we compare sketch mapping with landscape categories used in language through a case study.

\section{Study Area}

We conducted a case study in northwestern Bolivia in the Amazon rainforest (Figure 1). The landscape in the study area is primarily tropical rainforest that is seasonally flooded along rivers [45]. In 1995, the Madidi National Park and Integrated Management Area was created that covers an area of $18,957 \mathrm{~km}^{2}$ and is managed by the Servicio Nacional de Áreas Protegidas or SERNAP.

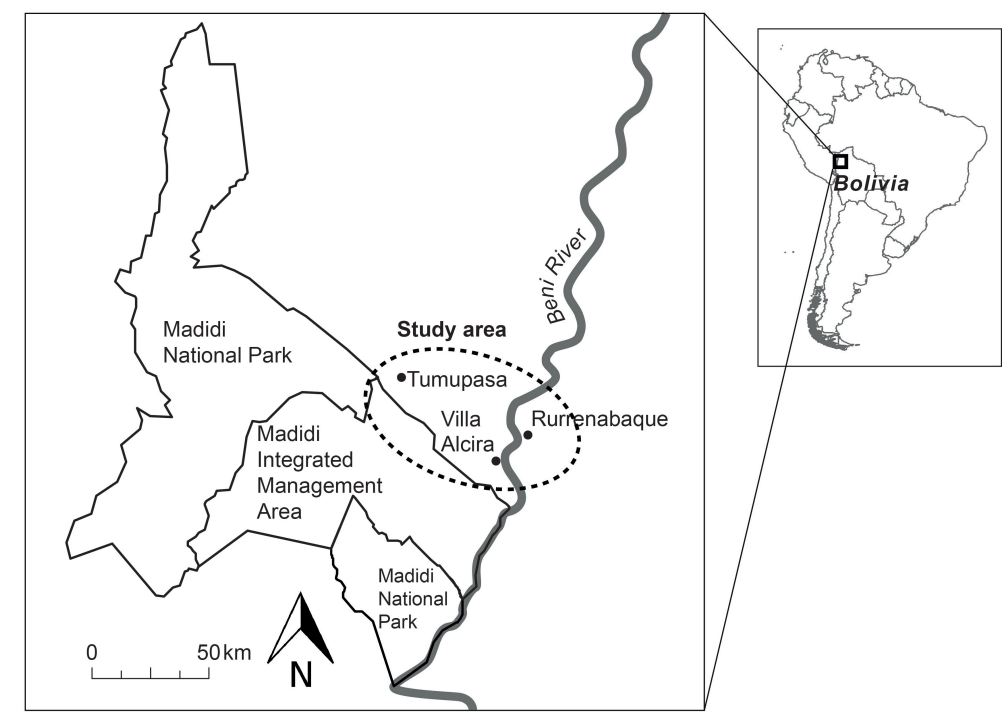

Figure 1. Location of study sites in Bolivia (source: authors, data: SERNAP). 
The area put under protection is inhabited by different groups of indigenous people, including the Takana $[46,47]$. Formerly following a hunter-gatherer lifestyle, Franciscan missionaries converted the Takana to small-scale agriculturalists [48]. The economy of contemporary Takana people is based on subsistence agriculture with crops such as rice, maize, beans and plantains, among others, complemented by hunting, fishing, and wage labor in the growing urban settlements. Most Takana people today are monolingual Spanish speakers [49] living in rural communities consisting of ten to thirty families. The population centers in the area are Tumupasa and the neighboring towns of San Buenaventura and Rurrenabaque. Despite the massive impact of colonization on their culture and language, Takana people maintain a comprehensive knowledge of local animal and plant species [48,50], and their ethnobotanical knowledge is well documented [51,52]. In 2003, the Takana indigenous council (Consejo Indígena del Pueblo Takana or CIPTA) obtained a communal land title for an indigenous territory (Territorio Comunitario de Origen, or TCO), which overlaps with the Madidi protected area where we conducted our study. This overlap resulted in tensions between protected area management and Takana people about access to natural resources [29]. In this context, maps and GIS are important management tools used both by the Takana council and the park administration. In the TCO Takana, participatory mapping has been used by the Wildlife Conservation Society (WCS) together with CIPTA in different Takana communities for natural resource management planning [47], resulting in conflicts about resource use in certain areas, in part because of what was not represented on maps. The study area is thus an ideal setting to explore participatory mapping of land use, and linking results back to decision-making and land management.

\section{Methodology}

In the following, we introduce the methods for sketch mapping and eliciting ethnoecological landscape categories. All data were collected during eight months of fieldwork between July 2012 and August 2015.

\subsection{Sketch Mapping with Local Participants}

Data collection for PGIS is often based on asking participants to draw on blank sheets of paper [31]. We refer to such hand-drawn representations as 'sketch maps', which are produced without topographic maps for guidance. We selected this technologically simple approach because it allows participants to choose how to represent the spatial information and does not presume prior knowledge of topographic maps [22,53] or impose certain forms of representation [54]. We asked participants to draw what they thought was important in the landscape in their community. Sheets of packing paper $(1 \mathrm{~m} \times 2 \mathrm{~m})$ and pencils in black, green, red and blue were provided to each participant. There was no time limitation, and participants indicated when they had finished drawing the sketch map. After the exercise, each participant explained their map to the researcher. Sketch mapping took place either in community workshops or at people's homes in three different communities. We selected these communities based on our previous work in the area, where we obtained consent from the community as well as the Takana council CIPTA to conduct this research [29,55]. We recruited participants by informing the community in Villa Alcira about the workshop at village meetings and the workshops conducted in Rurrenabaque and Tumupasa were advertised through the CIPTA council by inviting two people from each Takana community to join. Given that the workshop participants were predominantly male, we actively approached women in communities asking them to take part in a sketch mapping exercise. However, despite this additional measure, we did not achieve gender balance. In total, 29 participants drew a sketch map (22 men and 7 women). Most participants had completed basic formal obligatory education, except two participants who had very little or no formal education. All interactions with participants were in the local Spanish dialect and no translators were present. We categorized sketch maps by assessing the perspective, level of abstraction and scale participants used for mapping [42]. To analyze features, we relied on notes from the interviews with participants on the features they had represented (e.g., a plant drawn on a map was identified as a banana plant 
by the participant, and not by the researchers interpreting the drawing). We counted the number of feature types on each map, not the number of instances a feature was drawn. For example, we counted two different lines representing different trails as one feature type 'trail'. We then calculated arithmetic mean, median as well as the minimum and maximum number of feature types for all participants and compared them with landscape categories elicited using the methods described below.

\subsection{Eliciting Ethnoecological Landscape Categories through Field Walks and Interviews}

We combined methods informed from linguistics [56], ethnophysiography [57] and landscape ethnoecology [28] to elicit culturally recognized categories of landscape features. The methodology and elicited landscape terms are presented elsewhere in more detail [55]. For comprehensibility, we include here a brief description of the method used. We gained an overview of people's interaction with landscape features through participatory observation and field walks with local guides [28]. We then documented types of landscape features photographically and used these landscape photographs as prompts for semi-structured interviews [57]. In interviews, we asked participants to describe the landscape and its features as represented on the photograph and noted down all the terms mentioned for a photograph. In total, we conducted interviews with 19 participants (10 men and four women) and one group discussion with five women. We selected participants based on theoretical sampling using the criteria gender, experience in the landscape, and time living in the study area. We grouped the resulting categories into the same classes we used to organize the feature types from sketch maps. It is important to note that these classes were introduced to organize results, and do not follow participants' categorization principles [55]. Respecting time-constraints of participants as a principle of ethical research [58] and, for pragmatic reasons such as the geographic mobility of participants, it was often not possible for the same participant to conduct both an interview and a sketch mapping exercise. To assess the influence of the type of elicitation method given the same person and therefore the same ethnoecological knowledge, we obtained four sketch maps from participants several days or weeks after interviews to test the validity of our approach.

\section{Results}

First, we describe some general properties of sketch maps participants produced, before addressing the features they represented. Finally, we highlight differences between features on sketch maps and ethnoecological landscape categories used in language.

\subsection{Perspective, Scale and Abstraction in Sketch Maps}

We identified three different perspectives that participants chose for sketch mapping:

1. aerial view with a high vantage point and a perpendicular view to the Earth's surface, similar to aerial imagery (e.g., Figure 2),

2. sideways perspective (e.g., Figure 3),

3. a blend of aerial and sideways perspective (e.g., Figure 4). 


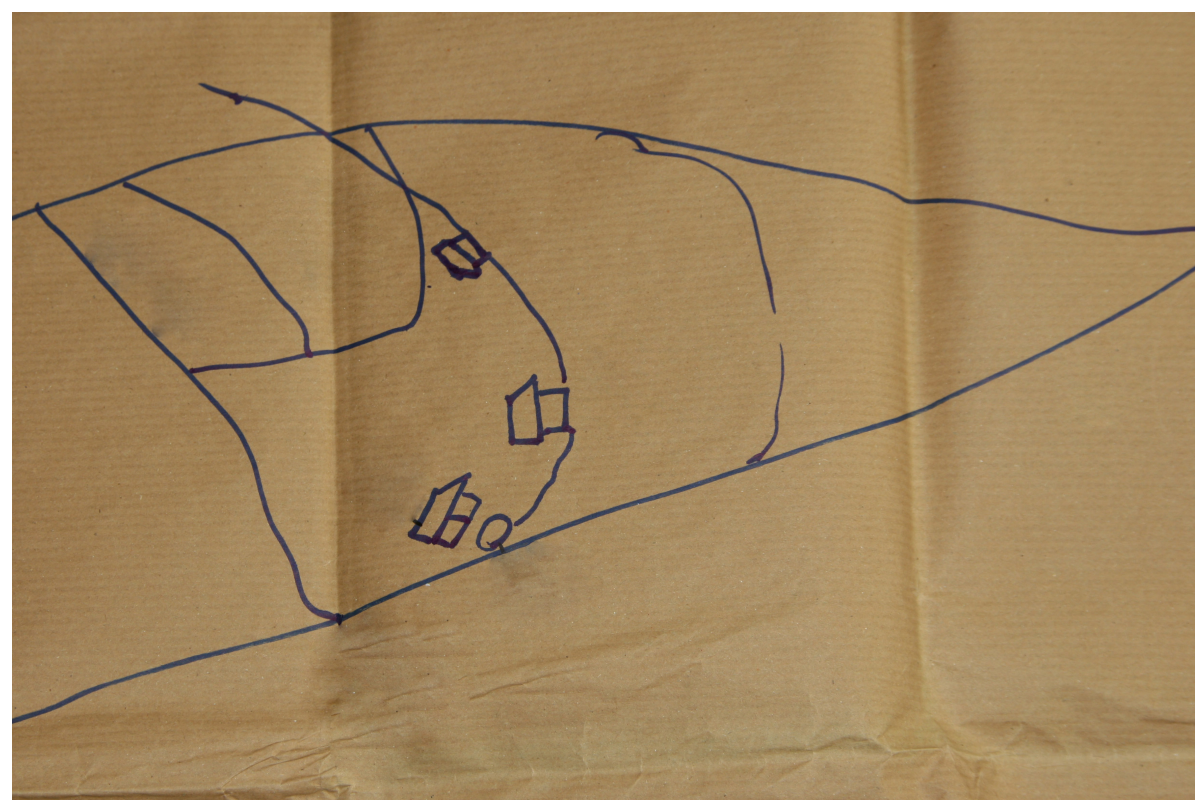

Figure 2. Example of sketch map with aerial view and high level of abstraction.

Of the 29 participants, 11 chose an aerial view, nine a sideways perspective and nine a blend of the two. Within maps combining aerial and sideways perspectives, two manifestations can be distinguished: one where the home/village is depicted at the center of the map in a sideways perspective and the surroundings in aerial view, such as agricultural fields and trails. The other depicts the village in an aerial view and the surroundings in a sideways perspective, often with a viewpoint from the river facing the mountain range in the background (e.g., Figure 4).

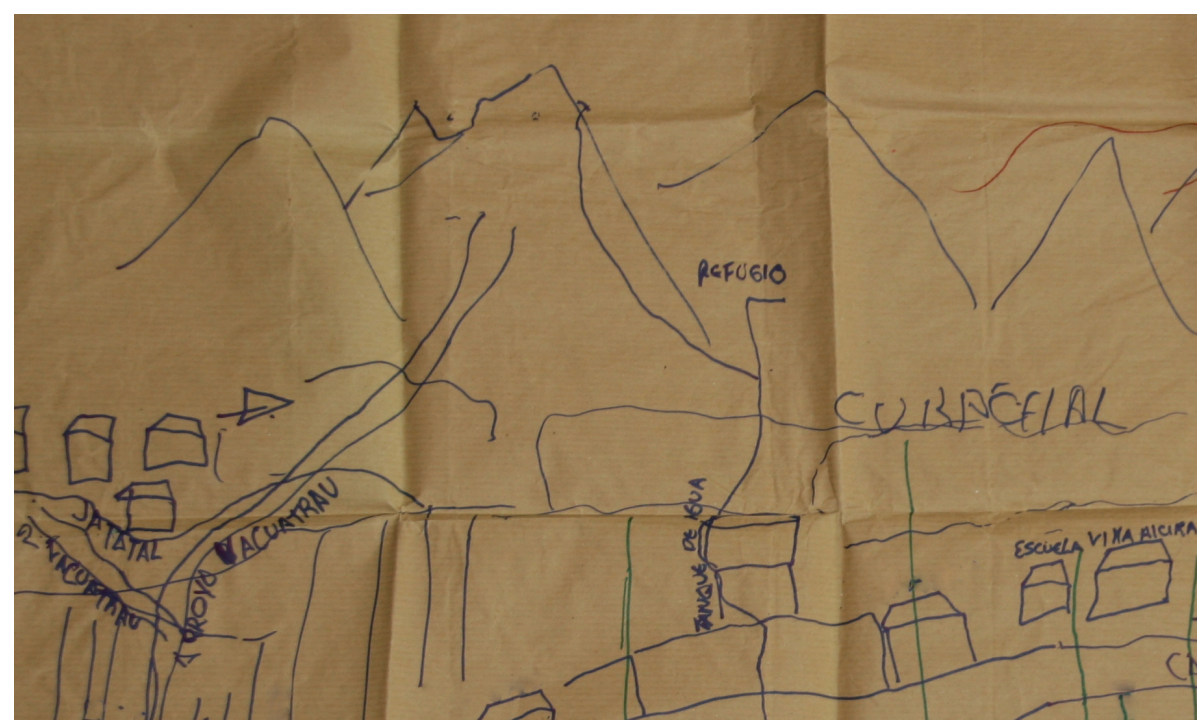

Figure 3. Example of a sketch map with a sideways perspective.

Rather than geographic scale, the scale on sketch maps often reflected the relative importance of certain areas: important places were exaggerated and thus took up more map space and, at the same time, were often drawn at the center of the sketch map, while elements considered less important were drawn at smaller scales. Some participants represented time necessary to travel between two locations as distance, rather than as Euclidean distance. For instance, a difficult to traverse part of the trail in the 
forest would be represented as a longer line on their sketch map, suggesting the importance of travel time in structuring space.

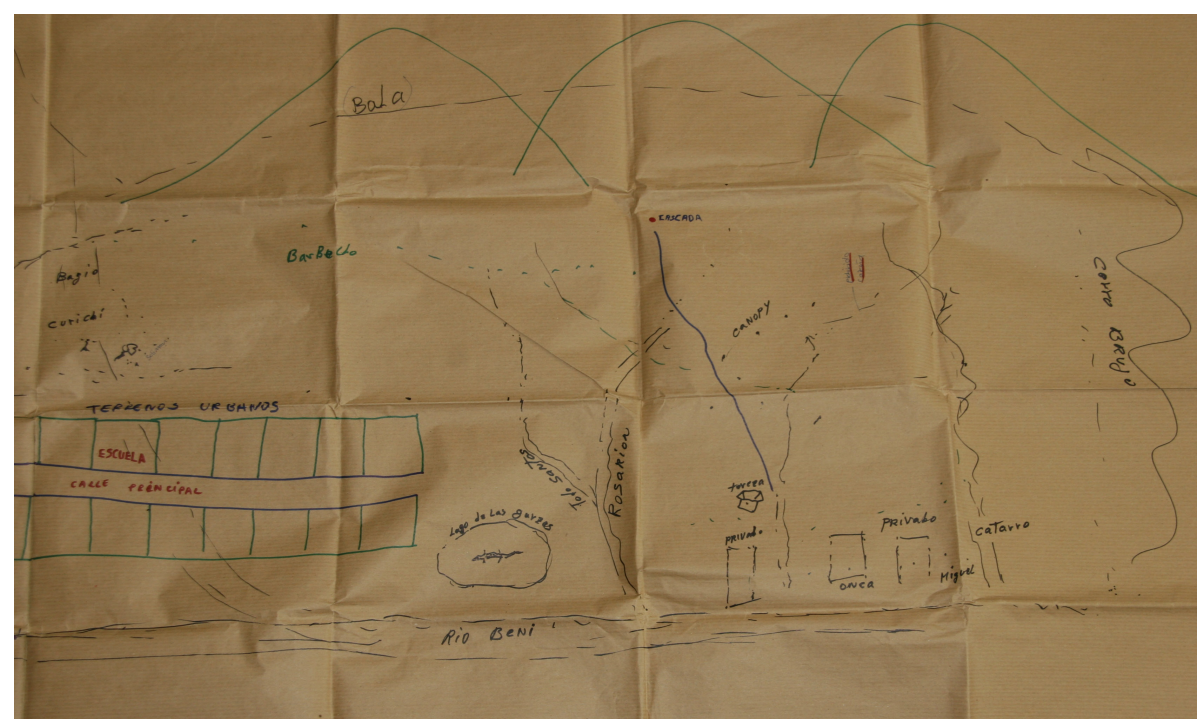

Figure 4. Example of a sketch map with a blend of aerial view and sideways perspective.

The level of abstraction participants chose varied considerably. Some participants drew a pictorial representation of the environment, using limited abstraction (e.g., Figure 3). Other participants represented their surroundings as an abstract network, representing trail crossings as nodes and the trails as edges in the network (e.g., Figure 2). Two participants chose to represent space as a highly abstracted network of trails and sites from an aerial perspective and included no other features on the map, indicating specific locations with toponyms while explaining the map. These sketch maps are highly similar to unelicited mappings of Takana consultants during participatory observation, for instance, a hunter explaining to his son where to find a herd of peccaries, or a mother explaining to her children where to find a medicinal tree. These unelicited maps often contained only the local trail system, a highly abstracted network representation, which was commonly drawn with a machete or a stick into soft ground, serving as a spatial reference for related oral explanations. The two participants who had chosen an aerial view with a high abstraction level had very little or no formal education and had never flown or seen their environment from such a vantage point that would allow exposure to an an aerial view, while participants familiar with standard cartographic maps through formal schooling chose a sideways or mixed perspective. This anecdotal evidence suggests that the level of formal schooling does not necessarily explain the method of representation participants chose. Next, we explore which specific features participants drew on their maps.

\subsection{Features Represented on Sketch Maps}

Overall, we documented 74 different feature types on sketch maps (Table 1). The most frequent features, which were drawn by 10 or more participants were casa (house), río (river), arroyo (stream), and carretera (road) (Table 1). Between two and nine participants drew the same 27 feature types, including camino (path), sendero (path, trail) and jatatal (area of Geonoma deversa palms). An example of features drawn on sketch maps can be seen in Figure 5. 
Table 1. Feature types drawn on sketch maps (categories shared with ethnoecological landscape categories represented in bold, plant names marked with * indicative of vegetation category).

\begin{tabular}{|c|c|c|}
\hline Feature (in Local Spanish Dialect) & Approximate English Translation & Number of Participants \\
\hline casa & house & 19 \\
\hline río & river & 19 \\
\hline arroyo & stream & 16 \\
\hline carretera & road & 11 \\
\hline camino & path & 8 \\
\hline jatatal & stand of Geonoma deversa & 8 \\
\hline sendero & trail, path & 8 \\
\hline cerro & hill, mountain & 6 \\
\hline chaco & agricultural plot & 5 \\
\hline comunidad & village, community & 5 \\
\hline barbecho & fallow plot & 4 \\
\hline cancha & soccer field & 4 \\
\hline lago & lake & 4 \\
\hline almendrillo & Dipteryx odorata & 3 \\
\hline arboles & trees & 3 \\
\hline canopy zip line & canopy zip line & 3 \\
\hline puente & bridge & 3 \\
\hline yucal & plot of Manihot esculenta & 3 \\
\hline bibosi * & Fig tree & 2 \\
\hline campamento & camp site & 2 \\
\hline chiquero & pig pen & 2 \\
\hline curichal & area of oxbow lakes & 2 \\
\hline escuela & school & 2 \\
\hline marfil * & ivory-nut palm (Pytelphas macrocarpa) & 2 \\
\hline pastizal & pasture & 2 \\
\hline personas & people & 2 \\
\hline piedra tallada & carved stone & 2 \\
\hline platanal & school & 2 \\
\hline puerto & port & 2 \\
\hline salitral & salt lick & 2 \\
\hline serranía & mountain range & 2 \\
\hline arbol de coco & coconut tree & 1 \\
\hline arbol de soliman & soliman tree & 1 \\
\hline área de cultivos & farming area & 1 \\
\hline área de plantas medicinales & medicinal plant area & 1 \\
\hline área forestal & lumbering area & 1 \\
\hline$a s a i ́$ * & Euterpe precatoria & 1 \\
\hline bajío & lowland & 1 \\
\hline barrero & area of mud & 1 \\
\hline cabaña & hut & 1 \\
\hline cachichira * & Sloanea obtusifolia & 1 \\
\hline calle & street & 1 \\
\hline cascada & waterfall & 1 \\
\hline cedro ${ }^{*}$ & Cedrela odorata & 1 \\
\hline cerdo & pig & 1 \\
\hline chancho & pig, collared peccary (Peccari tajacu) & 1 \\
\hline chaquillal & stand of Physocalymma scaberrimum & 1 \\
\hline colina & hill & 1 \\
\hline refugio & shelter & 1 \\
\hline gabú & Otoba parvifolia & 1 \\
\hline isla & island & 1 \\
\hline laguna & lagoon & 1 \\
\hline límites de comunidades & borders of communities & 1 \\
\hline maíz* & maize & 1 \\
\hline majal & stand of Oenocarpus bataua & 1 \\
\hline mango * & mango tree & 1 \\
\hline motacú * & Attalea phalerata & 1 \\
\hline nacientes de agua & watersheds & 1 \\
\hline naranja* & orange (tree) & 1 \\
\hline parabal & nesting area of macaws & 1 \\
\hline pato & duck & 1 \\
\hline peces & fish & 1 \\
\hline plantas & plants & 1 \\
\hline plátanos * & plantains & 1 \\
\hline poblaciones grandes & large settlements & 1 \\
\hline pueblo & town, village & 1 \\
\hline riachuelo & stream & 1 \\
\hline tanque de agua & water tank & 1 \\
\hline toronja * & grapefruit & 1 \\
\hline troncos de arboles & tree trunks & 1 \\
\hline vaca & cow & 1 \\
\hline villa & village, small town & 1 \\
\hline zona de cultivos & farming area & 1 \\
\hline zona de casería & hunting area & 1 \\
\hline
\end{tabular}




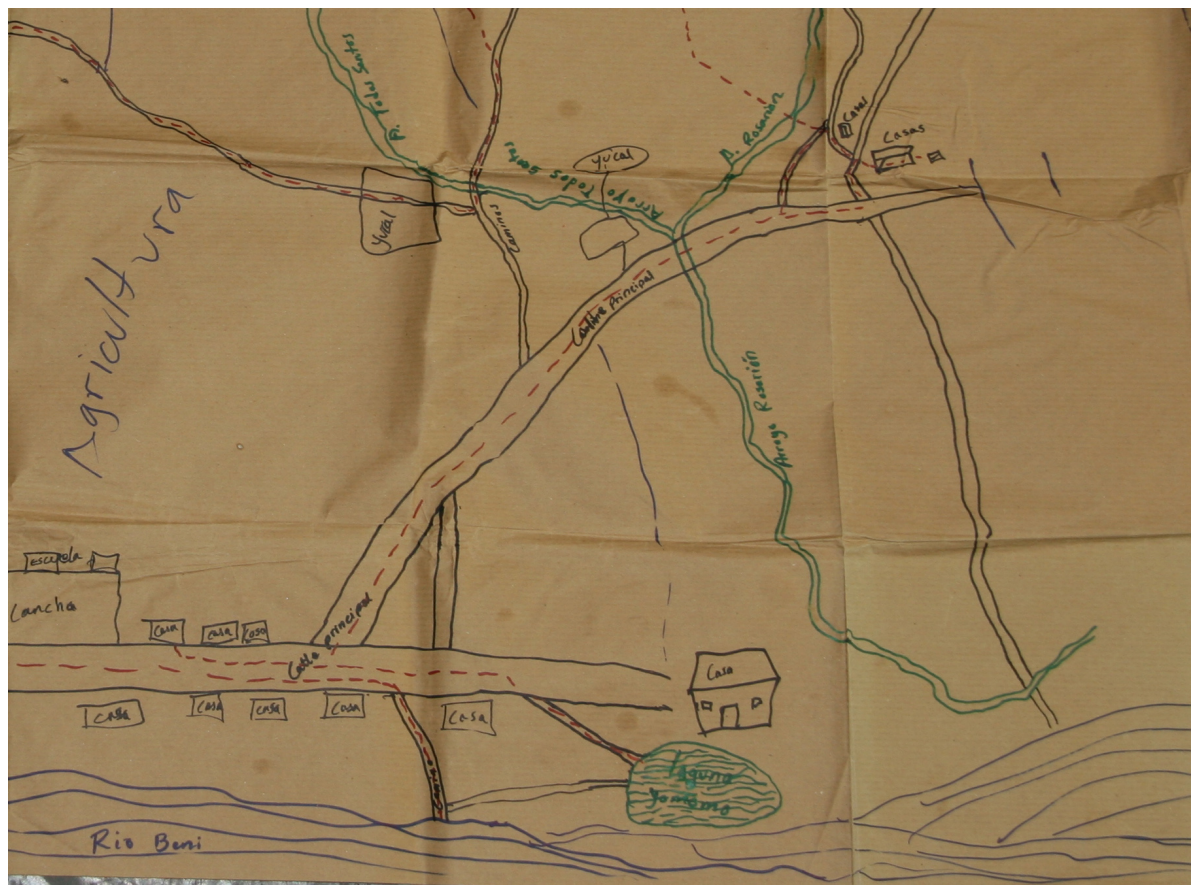

Figure 5. Snippet of a sketch map showing different features.

The frequency distribution showed a long tail, with 43 features each drawn by only one participant. Among these features were landscape elements such as bají (lowland), barrero (area of mud), riachuelo (small stream), isla (island), majal (stand of Oenocarpus bataua), but also drawings of people. Animals were also represented, including fish, cows, pigs and ducks. Trees were commonly drawn, such as palm trees of different species (majo, asai, motacú), timber trees (gabu, cedro) and fruit trees such as mango and orange trees (e.g., Figure 6).

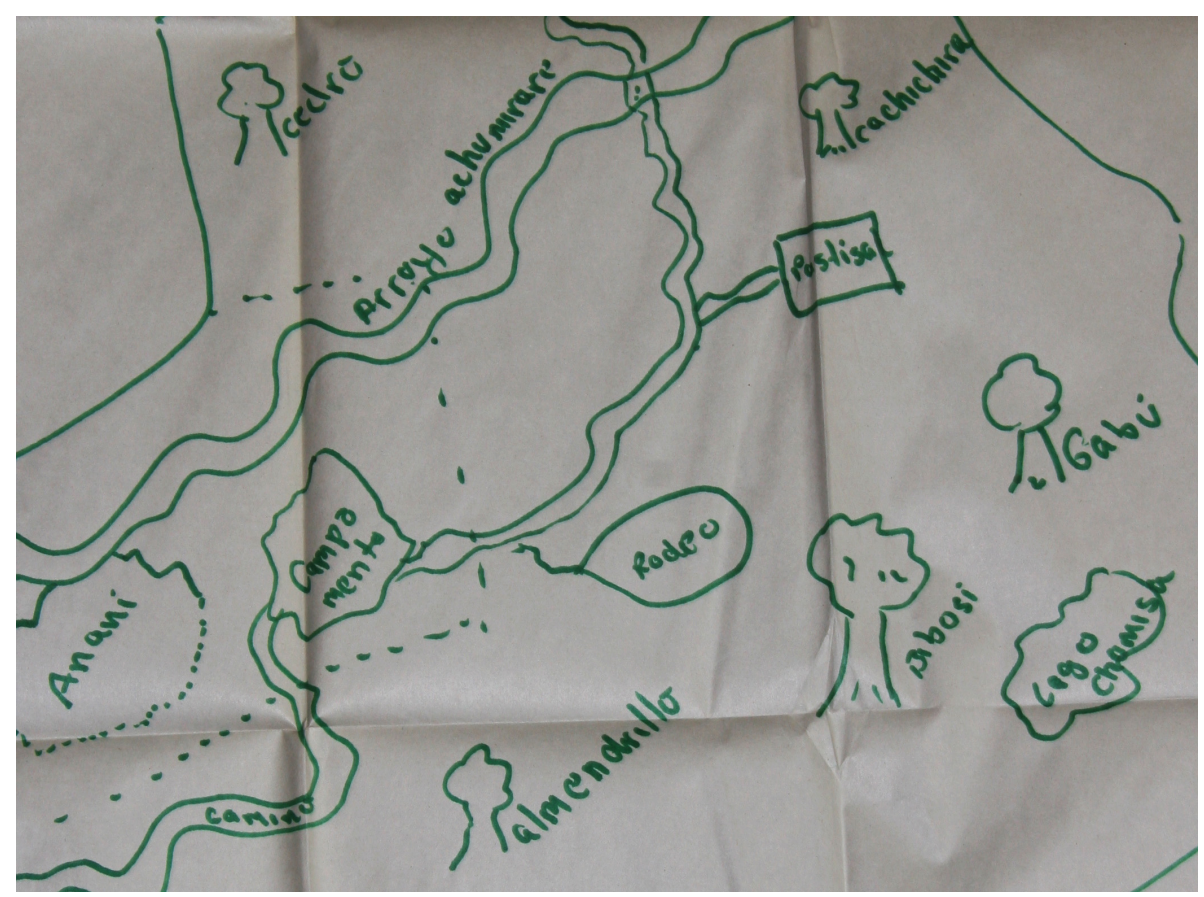

Figure 6. Snippet of a sketch map showing different vegetation features. 
The arithmetic mean of represented feature types was $6.52( \pm 3.28, n=29)$ and the median was 5 . The greatest number of feature types on any map was 15 ( $n=1$ participant), and the lowest number was $3(n=3)$. The sketch map with 15 feature types was drawn in a sideways perspective and those with three feature types were drawn in an aerial view. However, differences in the number of feature types between sketch maps with aerial view $(5.18 \pm 1.83, n=11)$, sideways perspective $(7.67 \pm 3.20, n=9)$, and mixed perspective $(7.00 \pm 4.36, n=9)$ were not significant (Kruskal-Wallis, $\chi^{2}=2.565, d f=2, p=0.227$ ). Importantly, participants did not draw all of the information that they deemed relevant on their sketch maps, but rather described some information. Eight participants drew certain features on the map (such as river and walking paths in the forest), but explained others during the experiment, such as the location of a jatatal (stand of Geonoma deversa, a palm species). Thus, although the location of a jatatal was very well known by participants, and was not considered a sacred location, this information was not often represented as a feature type on sketch maps. When we inquired further, several participants stated that they deemed a jatatal (and other local landscape categories) important, but did not represent it on the map because they considered it was 'local language' and was therefore not 'official' enough to go on the map. These observations led us to more closely examine the relation between mapped features and local terms for landscape.

\subsection{Comparing Features on Sketch Maps with Ethnoecological Landscape Categories}

Compared with the total of 74 different feature types on sketch maps, we elicited 156 landscape categories through interviews and field walks. For the small subset of four participants who conducted both sketch maps and interviews on landscape terms, we observed even more pronounced differences than across all participants. Interviews yielded consistently more landscape categories than sketch mapping, but there was no indication that more landscape categories elicited from an interview corresponds with more feature types drawn on the map for the same participant (Table 2).

Table 2. Direct comparison of features from sketch maps and interviews for four participants.

\begin{tabular}{ccc}
\hline Feature Types on Sketch Maps & Perspective on Sketch Map & Number of Landscape Terms from Interviews \\
\hline 15 & mixed & 46 \\
9 & mixed & 67 \\
7 & aerial & 46 \\
7 & aerial & 40 \\
\hline
\end{tabular}

In addition to the difference in numbers of elicited features, there was also relatively little overlap between the two methods. Only 23 ethnoecological landscape categories from the local vocabulary were also represented on sketch maps (marked in bold in Table 1). Thus, of 156 ethnoecological categories elicited through fieldwork, 134 were not drawn on maps. This overlap increases slightly if we count plants represented on sketch maps as indicator plants for vegetation categories, e.g., motacú (Attelea phalerata) for motacusal (stand of Attelea phalerata), which are marked with an asterix in Table 1. From the features represented on sketch maps, 51 were not documented as ethnoecological landscape categories. These features included anthropogenic elements (e.g., path, soccer field, school, and water tank), animals (e.g., pig, duck, cow, and fish) and people. Looking more closely into the differences between the geographic information elicited with the two methods, we found that the differences were unequal between different thematic classes (Figure 7). The difference was most pronounced for 'vegetation', with 60 ethnoecological categories compared to 18 feature types on maps, of which only three overlapped (jatatal, majal, and chaquillal). Also for 'agriculture', 'water', 'topography' and 'substrate', more ethnoecological categories were elicited than represented on sketch maps. However, for the anthropogenic and animal-related classes, sketch maps contained more features than were elicited as ethnoecological landscape categories (Figure 7), mainly because anthropogenic landscape elements such as infrastructure were not investigated as part of the ethnoecological landscape vocabulary. 


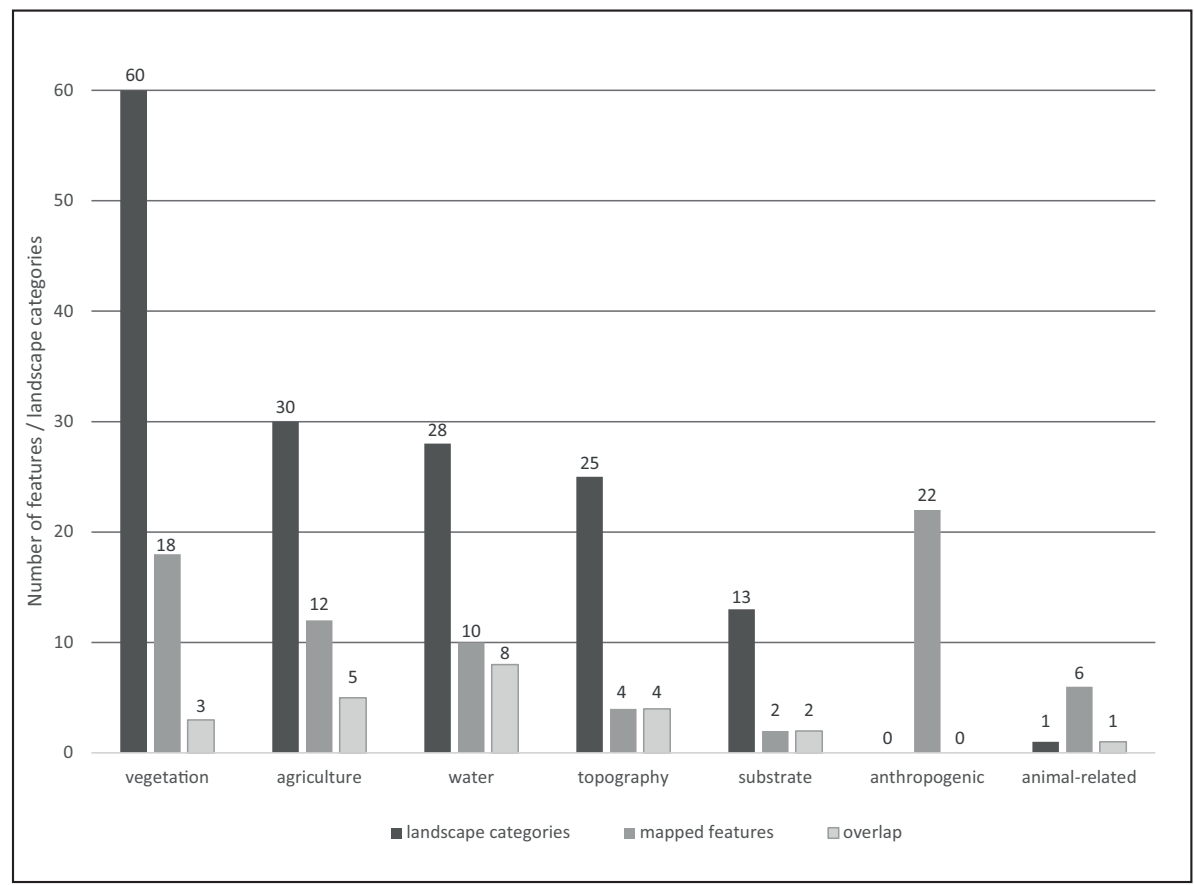

Figure 7. Comparison between ethnoecological landscape categories and features on sketch maps, including overlaps.

\section{Discussion}

We posed two research questions related to what landscape features people draw on sketch maps and how they go about doing so, as well as how features on sketch maps diverge from local landscape categories used in language. In the following, we first discuss our results before exploring implications for the collection of geographic information on land use through participatory sketch mapping.

\subsection{Use of Perspective, Scale and Abstraction on Sketch Maps}

As some participants were more familiar with standard cartographic maps than others, this may have influenced the perspective and representational choices that they made in mapping [59]. Participants more familiar with such maps through education may have been reproducing them, while participants with less exposure may not have been influenced in this way. However, level of education did not seem to directly relate to the perspective participants chose. Compared with studies conducted in more controlled (lab) environments, it would be challenging to investigate the influence of different factors such as education, age, gender, exposure to maps, and mapping task on the choice of perspective in our field setting. It is important to note that we were interested in mapping as an elicitation tool in a realistic setting, which was not so onerous that participants felt constrained or uncomfortable. Participants drew important features such as the village layout or agricultural plots larger than the surrounding areas. Similar findings have been reported from previous analyses of sketch maps where participants drew important areas and features they represented with positive memories larger [42]. Rather than comparing the sketch maps with standard cartographic maps and interpreting divergences as 'distortions' from a certain abstraction of an objectively measurable truth [60,61], we consider sketch maps as socially constructed meaningful representations embedded in a certain context, where the choice of different scales or non-Euclidean distance may indicate local importance or relevance. Although in this study we interpreted a detailed drawing of an animal or person as a low level of abstraction, we argue that these drawings may also be abstractions, only not in a graphical sense, but a cultural one. For instance, the drawing of a pig or a maize plant may represent subsistence agriculture, the backbone of Takana economy. Another example is the 
pictorial drawing of fish in the river, which participants may have decided to represent for highlighting the importance of fishing for Takana people. However, we would exercise caution in interpreting abstraction levels in sketch maps without accompanying ethnographic work, as abstraction and the number of features represented may depend on the drawing abilities of participants [62], which is contested in the literature $[42,61,63]$.

\subsection{Comparing Features on Sketch Maps with Ethnoecological Landscape Categories Used in Language}

Given the high diversification of landscape ethnoecological categorization in the speech-community, abstraction is essential for (sketch) mapping, and participants will suppress information that they do not deem relevant to the task at hand [63]. Thus, we would not expect to see the same number of features for both methods. During field walks and interviews, participants may have volunteered more information and were less likely to suppress knowledge about land use and landscape features. Another important aspect is the nature of the elicitation task, which influences what participants will choose to represent [63]. For instance, comparing our results from sketch mapping with a study on geographical categories using free-listing shows that the feature types from sketch maps resemble more closely categories elicited from US-American students on the question about 'things that could be portrayed on a map' than 'a kind of geographic feature' [64]. In our study, participants could have been influenced by previous experiences of participatory mapping related to management of the area, even though we explicitly avoided the use of the term sketch map in our elicitation.

Another important aspect influencing the number of feature types represented is individual drawing ability. Indeed, scholars have presented the considerable variation in (map) drawing abilities as a fundamental limitation of sketch mapping: 'One can ask people to draw maps, which I would not consider a very good procedure since it confounds drawing ability with geographical knowledge.' ([61], p. 69). However, sketch mapping is a widely established method for collecting geographic information, particularly in contexts where other forms of collecting land use information may not be feasible or culturally appropriate. As such, it is important to consider how such methods can be most appropriately used and combined in a particular setting. We therefore suggest that the combination of sketch mapping with methods that are focused on language, and, on the local categories for land use and landscape features, have the potential to build bottom-up conceptual ontologies. Together with more formal ontologies, these may provide a more holistic view by combining multiple perspectives of parcelling up the land into distinct, identifiable and ultimately mappable units.

\subsection{Implications for Using Sketch Maps in Decision-Making}

The difference between mapped features and categories used in language that we documented in this case study has important, and more general practical implications. The products of participatory mapping often form the basis for planning and management [65]. Consequently, what is not on the map is often also not considered in decision-making, which, if failing to adapt to local understandings can have tangible detrimental impact on the lives of people affected [8]. Although the general belief is that land use maps created through participatory processes better reflect local perceptions and priorities, our results showed that important landscape categories associated with informal land rights and certain behavioral rules [55], for example, mineral salt licks, old fallow plots, or patches of economically important plants, were not represented on sketch maps, and would therefore have been overlooked in a planning process. In fact, a community mapping project in the study area implemented by WCS in collaboration with CIPTA (WCS report, unpublished) resulted in maps that did not contain information on the existence or location of mineral salt licks or other culturally important sites and local land uses. These maps devoid of many important local land use categories (such as e.g., salitral, jatatal, barbecho) were then digitized and used for decision-making and planning. The resulting management plans were locally contested [29]. One issue was that areas containing salt licks (salitrales) were designated as hunting areas, contrary to Takana understandings of safeguarding animal populations by taking care of salt licks. Thus, as a practical outcome of this study, we created 
an illustrated dictionary of landscape terms in the local Spanish dialect and in the Takana language to be used as a guideline on what elements of the landscape and forms of land uses can be included in participatory mapping with local communities. Finally, several workshops were held with CIPTA and national park authorities from SERNAP on the importance of mapping local land use by incorporating map elements based on the terminology in the local dialect, e.g., instead of mapping 'second growth secondary tropical forest' mapping 'barbecho'. However, a follow-up study would be needed to assess the degree to which the capacity building and sensitization resulted in changing practices regarding mapping and landscape management.

Our results also indicate that folk ontologies may not only differ between different groups of people, as has been demonstrated [24,66], but also within the same group, depending on the method of elicitation. To capture the richness of local landscape categorizations in cross-cultural settings, if possible, participatory mapping should therefore be triangulated with other ethnographic approaches that focus more on the encoding of knowledge about landscape in language and do not presuppose a particular form of representation $[27,28]$. Given the increasing involvement of the public in the creation and use of geographic information through social media and citizen science projects, such considerations are also relevant for GIScience in general, as users may come up with diverse ontologies of the geographic domain. However, so far, much attention in the literature has been on using the data acquired through crowd-sourcing in a myriad of ways [67-69]. In contrast, more conceptual questions about crowd-sourced geographic data have so far received relatively little scientific attention $[66,70,71]$. If we want to develop GIS that allow the use and exchange of geographic information across different groups of people, an important step in this direction is to document multiple conceptual ontologies from the bottom up, so that they can be used as the basis for developing maps and GIS that better reflect the diverse ways that people conceptualize the world around them.

\section{Conclusions}

It is often assumed that participatory maps reflect local conceptualizations and land use, which can then be considered, for instance in resource management and spatial planning. However, our study showed considerable differences between features represented on sketch maps with ethnoecological landscape categories used in language. Ethnoecological landscape categories used by Takana indigenous people were more diversified than features represented on sketch maps, especially concerning vegetation. Although abstraction is necessary for mapping, our findings show that locally important features relating to land use, such as harvesting sites for certain plant species, were not represented on sketch maps, thus violating the assumption that sketch maps represent local land use and priorities. As such cultural features of the landscape were not represented on sketch maps, they are likely to be overlooked for management and planning. Therefore, we argue that, although participatory mapping of land use is an efficient way of gathering geographic information from local communities, such mapping should be accompanied by more language-based approaches. This will ensure that landscape categories used in the language of a local community can be taken as the basis for developing spatial representations that will indeed better reflect local conceptualizations.

Acknowledgments: We are indebted to the people who participated in interviews and sketch mapping exercises, and to local guides who showed us their view and language about landscape during fieldwalks. The Consejo Indígena del Pueblo Takana in Tumupasa (CIPTA) and the Servicio Nacional de Áreas Protegidas SERNAP in La Paz and San Buenaventura granted research permits. This work was supported from the 'Forschungskredit' of the University of Zurich (Grant No. FK-13-104), the Hans Vontobel Foundation, the Maya Behn-Eschenburg Foundation, the Ormella Foundation, and the Parrotia Foundation. We thank the two anonymous reviewers for their comments on a previous version of this manuscript.

Author Contributions: F.M.W. and R.S.P. conceived and designed the study, F.M.W. collected and analyzed the data; F.M.W. and R.S.P. wrote the paper.

Conflicts of Interest: The authors declare no conflict of interest. 


\section{Abbreviations}

The following abbreviations are used in this manuscript:

CIPTA Consejo Indígena del Pueblo Takana (Takana indigenous council)

GIS Geographic Information System

TCO Tierra Comunitaria de Origen (indigenous territory)

PGIS Participatory Geographic Information System

\section{References}

1. Bruggeman, D.; Meyfroidt, P.; Lambin, E.F. Production forests as a conservation tool: Effectiveness of Cameroon's land use zoning policy. Land Use Policy 2015, 42, 151-164.

2. Foley, J.A. Global Consequences of Land Use. Science 2005, 309, 570-574.

3. Pielke, R.A.; Pitman, A.; Niyogi, D.; Mahmood, R.; McAlpine, C.; Hossain, F.; Goldewijk, K.K.; Nair, U.; Betts, R.; Fall, S.; et al. Land use/land cover changes and climate: Modeling analysis and observational evidence. Wiley Interdiscip. Rev. Clim. Chang. 2011, 2, 828-850.

4. Comber, A.J.; Fisher, P.F.; Wadsworth, R.A. What is land cover? Environ. Plann. B Plan. Des. 2005, 32, $199-209$.

5. Crampton, J.W. Maps as social constructions: Power, communication and visualization. Prog. Hum. Geogr. 2001, 25, 235-252.

6. Harvey, F.; Chrisman, N. Boundary objects and the social construction of GIS technology. Environ. Plan. A 1998, 30, 1683-1694.

7. Wood, D. The Power of Maps; Guilford Press: New York, NY, USA, 1992.

8. Robbins, P. Fixed categories in a portable landscape: The causes and consequences of land-cover categorization. Environ. Plan. A 2001,33, 161-179.

9. Hoeschele, W. Geographic information engineering and social ground truth in Attappadi, Kerala State, India. Ann. Assoc. Am. Geogr. 2000, 90, 293-321.

10. Abbot, J.; Chambers, R.; Dunn, C.; Harris, T.; Merode, E.; Porter, G.; Townsend, J.; Weiner, D. Participatory GIS: Opportunity or oxymoron? PLA Notes 1998, 33, 27-33.

11. Chambers, R. The Origins and Practice of Participatory Rural Appraisal. World Dev. 1994, 22, 953-969.

12. Bernard, E.; Barbosa, L.; Carvalho, R. Participatory GIS in a sustainable use reserve in Brazilian Amazonia: Implications for management and conservation. Appl. Geogr. 2011, 31, 564-572.

13. Cronkleton, P.; Albornoz, M.A.; Barnes, G.; Evans, K.; Jong, W. Social geomatics: Participatory forest mapping to mediate resource conflict in the Bolivian Amazon. Hum. Ecol. 2010, 38, 65-76.

14. Fraser, E.D.G.; Dougill, A.J.; Mabee, W.E.; Reed, M.; McAlpine, P. Bottom up and top down: Analysis of participatory processes for sustainability indicator identification as a pathway to community empowerment and sustainable environmental management. J. Environ. Manag. 2006, 78, 114-127.

15. Jankowski, P. Towards participatory geographic information systems for community-based environmental decision making. J. Environ. Manag. 2009, 90, 1966-1971.

16. Mapedza, E.; Wright, J.; Fawcett, R. An investigation of land cover change in Mafungautsi Forest, Zimbabwe, using GIS and participatory mapping. Appl. Geogr. 2003, 23, 1-21.

17. Amelot, X. Cartographie participative pour le développement local et la gestion de l'environnement à Madagascar: Empowerment, impérialisme numérique ou illusion participative? L'Information Géographique 2013, 77, 47.

18. Brown, G.; Kyttä, M. Key issues and research priorities for public participation GIS (PPGIS): A synthesis based on empirical research. Appl. Geogr. 2014, 46, 122-136.

19. Dunn, C.E. Participatory GIS a people's GIS? Prog. Hum. Geogr. 2007, 31, 616-637.

20. Duvail, S. Cartographies participatives et conflits territoriaux. Revue d'ethnoécologie 2017, doi:10.4000/ ethnoecologie.3039.

21. Newing, H.; Eagle, C.; Puri, R.; Watson, C.W. Conducting Research in Conservation: A Social Science Perspective; Routledge: London, UK; New York, NY, USA, 2011.

22. Peluso, N.L. Whose woods are these? Counter-mapping Forest Territories in Kalimantan, Indonesia. Antipode $1995,27,383-406$. 
23. Weiner, D.; Harris, T.M.; Craig, W.J. Community participation and geographic information systems. In Community Participation and Geographic Information Systems; Craig, W.J., Harris, T.M., Weiner, D., Eds.; Taylor \& Francis: London, UK; New York, NY, USA, 2002; pp. 3-17.

24. Wellen, C.C.; Sieber, R.E. Toward an inclusive semantic interoperability: The case of Cree hydrographic features. Int. J. Geogr. Inf. Sci. 2013, 27, 168-191.

25. Schuurman, N. Formalization matters: Critical GIS and ontology research. Ann. Assoc. Am. Geogr. 2006, 96, 726-739.

26. Burenhult, N.; Levinson, S.C. Language and landscape: A cross-linguistic perspective. Lang. Sci. 2008, 30, 135-150.

27. Mark, D.M.; Turk, A.G.; Burenhult, N.; Stea, D. Landscape in Language; John Benjamins Publishing: Amsterdam, The Netherlands; Philadelphia, PA, USA, 2011.

28. Johnson, L.; Hunn, E. Landscape Ethnoecology; Berghahn Books: New York, NY, USA, 2010.

29. Wartmann, F.M.; Haller, T.; Backhaus, N. 'Institutional Shopping' for Natural Resource Management in a Protected Area and Indigenous Territory in the Bolivian Amazon. Hum. Organ. 2016, 75, 218-229.

30. Wang, J.; Worboys, M. Ontologies and representation spaces for sketch map interpretation. Int. J. Geogr. Inf. Sci. 2017, 31, 1697-1721.

31. Smith, D.A. Participatory mapping of community lands and hunting yields among the Buglé of western Panama. Hum. Organ. 2003, 62, 332-343.

32. Boschmann, E.E.; Cubbon, E. Sketch maps and qualitative GIS: Using cartographies of individual spatial narratives in geographic research. Prof. Geogr. 2014, 66, 236-248.

33. Downs, R.M.; Stea, D. Maps in Minds: Reflections on Cognitive Mapping; Harper and Row: New York, NY, USA, 1977.

34. Kitchin, R.M. Cognitive maps: What are they and why study them? J. Environ. Psychol. 1994, 14, 1-19.

35. Lynch, K. The Image of the City; MIT Press: Cambridge, MA, USA, 1960.

36. Tversky, B. Cognitive maps, cognitive collages, and spatial mental models. In Spatial Information Theory a Theoretical Basis for GIS; Frank, A.U., Campari, I., Eds.; Springer: Berlin/Heidelberg, Germany, 1993; pp. 14-24.

37. Byrne, R.W. Memory for urban geography. Q. J. Exp. Psychol. 1979, 31, 147-154.

38. Tversky, B. Distortions in memory for maps. Cogn. Psychol. 1981, 13, 407-433.

39. Feinberg, R.; Dymon, U.J.; Paiaki, P.; Rangituteki, P.; Nukuriaki, P.; Rollins, M. 'Drawing the Coral Heads': Mental Mapping and its Physical Representation in a Polynesian Community. Cartogr. J. 2003, 40, $243-253$.

40. Kelly, J. Maori maps. Cartogr. Int. J. Geogr. Inf. Geovisualization 1999, 36, 1-30.

41. Sletto, B.I. "We Drew What We Imagined". Participatory Mapping, Performance, and the Arts of Landscape Making. Curr. Anthropol. 2009, 50, 443-476.

42. Gieseking, J.J. Where We Go From Here: The Mental Sketch Mapping Method and Its Analytic Components. Qual. Inq. 2013, 19, 712-724.

43. Burenhult, N. Streams of words: Hydrological lexicon in Jahai. Lang. Sci. 2008, 30, 182-199.

44. Bromhead, H. Ethnogeographical categories in English and Pitjantjatjara/Yankunytjatjara. Lang. Sci. 2011, $33,58-75$.

45. Fuentes, A. Una introducción a la vegetación de la región de Madidi. Ecol. Boliv. 2005, 40, 1-31.

46. Ferrié, F. El Tuichi o el deslizamiento de una frontera. In Las Tierras Bajas de Bolivia: Miradas Históricas y Antropológicas; Villar, D., Combès, I., Eds.; El País: Santa Cruz de la Sierra, Bolivia, 2012; pp. 107-119.

47. Lehm, Z. Los Takanas. In Las tierras bajas de Bolivia.Miradas históricas y antropológicas; Villar, D.; Combès, I., Eds.; El País: Santa Cruz de la Sierra, Bolivia, 2012; pp. 177-197.

48. CIPTA. Aibawekuana etse Pamapa Aibawekuana Takana; Estado Plurinacional de Bolivia, Ministerio de Educación: La Paz, Bolivia, 2010.

49. Pinto Mosqueira, G. Lenguaje y Habla Popular en el Pueblo Cruceño-Camba. Available online: https://issuu.com/richardosinagamunoz/docs/cuaderno_de_trabajo_no._6_-lenguaj (accessed on 2 Novemer 2017).

50. Tejada, R.; Chao, E.; Gómez, H.; Painter, L.R.E.; Wallace, R.B. Evaluación sobre el uso de la fauna silvestre en la Tierra Comunitaria de Origen Tacana, Bolivia. Ecol. Boliv. 2006, 41, 138-148. 
51. Bourdy, G.; DeWalt, S.J.; Chávez Michel, L.R.; Roca, A.; Deharo, E.; Muñoz, V.; Balderrama, L.; Quenevo, C.; Gimenez, A. Medicinal plants uses of the Tacana, an Amazonian Bolivian ethnic group. J. Ethnopharmacol. 2000, 70, 87-109.

52. DeWalt, S.J.; Bourdy, G.; Michel, L.R.C.; Quenevo, C. Ethnobotany of the Tacana: Quantitative inventories of two permanent plots of northwestern Bolivia. Econ. Bot. 1999, 53, 237-260.

53. Tobias, T.N. Living Proof. The Essential Data-Collection Guide for Indigenous Use-and-Occupancy Map Surveys; Ecotrust Canada: Vancouver, BC, Canada, 2009.

54. Rundstrom, R.A. GIS, Indigenous Peoples, and Epistemological Diversity. Cartogr. Geogr. Inf. Syst. 1995, 22, 45-57.

55. Wartmann, F.M.; Purves, R.S. 'This is not the jungle, this is my barbecho': Semantics of ethnoecological landscape categories in the Bolivian Amazon. Landsc. Res. 2017, 1-18, doi:10.1080/01426397.2016.1269882.

56. Bohnemeyer, J.; Burenhult, N.; Enfield, N.J.; Levinson, S.C. Landscape terms and place names elicitation guide. In Field Manual; Asifa, M., Ed.; Max Planck Institute for Psycholinguistics: Nijmegen, The Netherlands, 2004; pp. 75-79.

57. Mark, D.M.; Turk, A.G. Landscape categories in Yindjibarndi: Ontology, environment and language. In Spatial Information Theory. Foundations of Geographic Information Science; Kuhn, W., Worboys, M., Timpf, S., Eds.; Springer: Berlin, Germany; New York, NY, USA, 2003; pp. 28-45.

58. Association of Social Anthropologists of the UK and the Commonwealth (ASA). Ethical Guidelines for Good Research Practice; Association of Social Anthropologists of the UK and the Commonwealth (ASA): London, UK, 2011.

59. Davies, C.; Uttal, D.H. Map use and the development of spatial cognition. In The Emerging Spatial Mind; Plumert, J.M., Spencer, J.P., Eds.; Oxford University Press: New York, NY, USA, 2007; pp. 219-247.

60. Downs, R.M.; Stea, D. (Eds.) Image and Environment: Cognitive Mapping and Spatial Behavior; Transaction Publishers: New Brunswick, NJ, USA; London, UK, 1973.

61. Tobler, W.R. The geometry of mental maps. In Spatial Choice and Spatial Behavior; Golledge, R.G., Rushton, G., Eds.; Ohio State University Press: Columbus, OH, USA, 1976; pp. 69-81.

62. Kitchin, R.; Freundschuh, S. (Eds.) Cognitive Mapping: Past, Present, and Future; Routledge: London, UK; New York, NY, USA, 2000.

63. Murray, D.; Spencer, C. Individual differences in the drawing of cognitive maps: The effects of geographical mobility, strength of mental imagery and basic graphic ability. Trans. Inst. Br. Geogr. 1979, 4, 385-391.

64. Smith, B.; Mark, D.M. Geographical categories: An ontological investigation. Int. J. Geogr. Inf. Sci. 2001, 15, 591-612.

65. Hodgson, D.L.; Schroeder, R.A. Dilemmas of Counter-Mapping Community Resources in Tanzania. Dev. Chang. 2002, 33, 79-100.

66. Klippel, A.; Mark, D.; Wallgrün, J.O.; Stea, D. Conceptualizing Landscape. A Comparative Study of Landscape Categories with Navajo and English-Speaking Participants. In Spatial Information Theory; Fabrikant S., Raubal M., Bertolotto M., Davies C., Freundschuh S., Bell S., Eds.; Springer: Cham, Switzerland, 2015; pp. 268-288.

67. Atzmanstorfer, K.; Resl, R.; Eitzinger, A.; Izurieta, X. The GeoCitizen-approach: Community-based spatial planning-An Ecuadorian case study. Cartogr. Geogr. Inf. Sci. 2014, 41, 248-259.

68. Camponovo, M.E.; Freundschuh, S.M. Assessing uncertainty in VGI for emergency response. Cartogr. Geogr. Inf. Sci. 2014, 41, 440-455.

69. Connors, J.P.; Lei, S.; Kelly, M. Citizen science in the age of neogeography: Utilizing volunteered geographic information for environmental monitoring. Ann. Assoc. Am. Geogr. 2012, 102, 1267-1289.

70. Dodge, M.; Kitchin, R. Crowdsourced cartography: Mapping experience and knowledge. Environ. Plan. A 2013, 45, 19-36.

71. Klippel, A.; Weaver, C.; Robinson, A.C. Analyzing cognitive conceptualizations using interactive visual environments. Cartogr. Geogr. Inf. Sci. 2011, 38, 52-68.

(C) 2017 by the authors. Licensee MDPI, Basel, Switzerland. This article is an open access article distributed under the terms and conditions of the Creative Commons Attribution (CC BY) license (http:/ / creativecommons.org/licenses/by/4.0/). 